\title{
Ultrastuctural changes in certain nymphal tissues of schistocerca gregaria (orthoptera: acrididae) by some chitin synthesis inhibitors.
}

\author{
Bakr, R.F. ${ }^{1}$; Ghoneim, K.S. ${ }^{2}$; Bream, A.S. ${ }^{2}$; Al-Dali, A.G. ${ }^{2}$ and Tanani, M.A. ${ }^{2}$ \\ 1- Department of Entomology, Faculty of Science, Ain Shams University; \\ 2-Department of Zoology, Faculty of Science, Al-Azhar University, Cairo, Egypt. \\ For Corresponding: kar_ghoneim@yahoo.com
}

\section{ABSTRACT}

Flufenoxuron caused a blockage of the production of cuticle of the last instar nymphs since its thickness remained unchanged while that of control congeners increased in thickness as the development proceeded. The formation of endocuticle was prohibited, so the epicuticle and exocuticle did not properly attached to the epidermis. The epidermis appeared with irregularly distributed cells underneath the cuticle. On the other hand, Lufenuron exhibited more dangerous effects. The epidermis was degenerated and detached from the endocuticle which could not distinguish from the exocuticle.

The available electron micrographs reveal several dangerous effects of Flufenoxuron on the thoracic muscles such as distortion shape of the $\mathrm{Z}$ line and disorganization of $\mathrm{A}, \mathrm{I}$ and $\mathrm{H}$ bands, appearance of gaps and vacuoles in the sarcomere. Similar effects were recorded for Lufenuron beside the complete distortion of the $\mathrm{Z}$ disc.

Flufenoxuron affected the ultrastructure of mid-gut such as destruction of the cell vacuolization and a rupture of the epithelial walls. In respect to Lufenuron, some signs of morbidity in both nuclei and cytoplasm of the epithelial cells were observed, such as curling and rupturing of the microvilli and the formation of large area of necrosis in a vacuolated cytoplasm.

Flufenoxuron caused several ultrastructural changes in the intracellular organelles of last instar nymphs. The mitochondria appeared generally in an irregular shape. Their two membranes were not demarcated with loss of cristae but increased granules. Morphology and of Golgi bodies was remarkably influenced and some of them were fragmented into small particles. The secretion granules associating the Golgi bodies disappeared. The limiting membranes of lysosomes were ruptured. The margination and nuclear chromatin seemed to be early changed leading to the cell death. Lufenuron, on the other hand, caused many serious ultrastructural changes since the mitochondrial cristae were partially or totally lost. Some mitochondria appeared swollen with irregular shape while others appeared greatly elongated with prominent cristae. The mitochondrial membranes were not demarcated, and some mitochondria were filled with dark electron dense granules. Also, the nuclear membrane was disrupted. As well as, the lysosomes and Golgi bodies were hypertrophied with different deformities.

Kew Words: Schistocerca gregaria, Flufenoxuron, Lufenuron, nymphal instar, ultrastructure, histopathology, integument, muscles, mid gut, mitochondria, lysosomes, Golgi bodies, nuclear membrane, cytoplasm. 


\section{INTRODUCTION}

Chitin synthesis inhibitors (CSIs) interfere with chitin biosynthesis in insects (Gijswijt et al., 1979) and thus prevents moulting or produces an imperfect cuticle (Hammock and Quistad, 1981). These compounds are effective suppressors of development for the entire life cycle on insects (Verloop and Ferrell, 1977). However, these compounds, also, affect the hormonal balance in insects, thereby resulting in physiological disturbances, such as inhibition of DNA synthesis (DeLoach et al., 1981); alteration of carbohydrates (Ishaaya and Ascher, 1977); increase in phenyoxidase activity (Deul et al., 1978); cuticular lipids (Salama et al., 1976) and microsomal oxidase (Yu and Terriere, 1977). The most important group of CSIs is benzoylphenyl ureas which have been subjected to intensive investigation because of their commercial importance and their interference with the moulting and other physiological processes in several insect species (Ishaaya, 1990; Soltani et al., 1993; Casida and Quistad, 1998).

Compared with knowledge of the developmental, morphogenic and reproductive effects of CSIs, knowledge of their effects on tissue architecture and cell ultrastructure is somewhat poor. However, the histopathological and/or ultrastructural chamges in some insect species had been investigated by some CSIs such as Dimilin against Locusta migratoria (Clarke et al., 1977), Pectinophora gossypiella (Saad et al., 1985), Chironomus decorus (Pelsu, 1985), Musca domestica (Bakr, 1986), Culex pipiens (Bakr et al., 1997) and Spodoptera exigua (Younes et al., 2000); triflumuron against C. decorus and Tanypus grodhaus (Pelsu, 1985) and Tribolium castaneum (Parween, 1997); buprofezin against Trialeurodes vaporiorum (De Cock and Degheele, 1991). The present work aimed to investigate the histopathological effects of the CSIs Flufenoxuron and Lufenuron and ultrastructural changes in the desert locust Schistocerca gregaria.

\section{MATERIALS AND METHODS}

\section{Experimental Insect:}

A gregarious stock culture of Schistocerca gregaria (Forsk.) was raised by a sample from the established culture of Locust and Grasshopper Res. Division, Agric. Res. Center, Giza, Egypt. The insects were reared under crowded breeding conditions outlined by Hunter-Jones (1961) and Hassanein (1965). Newly hatched hoppers were kept in wooden cages with wire-gauze sides $(40 \times 40 \times 60 \mathrm{~cm})$ and small door in the upperside to allow the daily feeding and cleaning routine. The bottom was covered with $20 \mathrm{~cm}$ layer of sterilized sand. Each cages was equipped internally with $60 \mathrm{~W}$ electric bulb for lightening (17:7 LD) and warming (32 \pm 2 C.). The relative humidity varied from $70-80 \%$ following the introduction of fresh food plant to $60-70 \%$ several hours later.

Successive generations were raised before obtaining the nymphs for the present experimental work. Fresh food plant was clover Medicago sativa along the period of study except few weeks every year because of the absence of this plant species. During these weeks, insects were fed on Sesbania eagyptiaca. All experiments were conducted with $M$. sativa only.

\section{Nymphal Treatments with Chitin Biosynthesis Inhibitors:}

A technical concentrate $10 \%$ of Flufenoxuron (Cascade, CAS-101463101463) was used. Its chemical name is $\mathrm{N}-\{\{\{4-\{2$-chloro-4-(trifluoromethyl) phenoxy $\}$-2-fluorophenyl $\}$ amino $\}$ carbonyl $\}-2,6$-difluorobenzamide. A similar 
concentrate of Lufenuron ( Match, CGA-184699 ) was used. Its chemical formula is: $\mathrm{N}-\{\{\{2,5$-dichloro-4-(1,1,2,3,3-hexafluoro-propoxyl)-phenyl $\} \quad$ amino $\} \quad-2,6-$ difluorobenzamide (CA) $\}\}\}$. Feeding technique was applied using fresh clean clover leaves ( $M$. sativa) after dipping for 3 minutes in the concentration level. Three replicates (10 nymphs/rep.) were carried out for each treatment. Each individual nymph was kept in a suitable glass vial whose bottom covered with a thin layer of sterilized sand. All vials were carefully located in a cage provided with a suitable electric bulb for lightening and warming.

\section{Histopathological and Ultrastuctural Techniques:}

After treatment of the 1-day old penultimate instar nymphs of S. gregaria with $1000 \mathrm{ppm}$ of Flufenoxuron or Lufenuron, the histopathological and ultrastuctural effects were examined in the cuticle, muscles, mid-gut of the 1-day old last instar nymphs. For this purpose, a representative nymph of each group was dissected and transected, fixed as soon as possible in 3\% phosphate buffered glutaraldehyde $(\mathrm{pH}$ 7.3) for 2 hours. After two rinses in the buffer (for a period of 4 hours) the specimens are post fixed in $1 \%$ buffered osmium tetroxide for 1 hour at $4^{\circ} \mathrm{Control}$ congeners (Brissan et al., 1996).

The tissue pieces were washed twice in a buffer for 30 minutes. The specimens are then dehydrated in seconding grades of ethanol, 50, 70, 80, 90 and $100 \%$. The specimens were cleared in toluene for 10 minutes and then embedded in the resin of choic Epon. Semithen sections are cut from these blocks (stained with toluidine blue) and examined by the light microscope (Spnrr, 1969).

Ultrathin sections obtained from selected blocks were mounted on copper grids stained with uranyl acetate and lead citrate and then examined with Jol 1010 transmission electron microscope (Reynolds, 1963). This technique was carried out at Regional Center for Mycology and Biotechnology, Al-Azhar University, Madenit Nasr, Cairo.

\section{RESULTS}

The histopathological and ultrastuctural investigations were carried out for 1- day old last instar nymphs of $S$. gregaria after feeding the 1- day old penultimate instar nymphs on a fresh food plant treated with 1000 ppm of Flufenoxuron, Lufenuron, Tebufenozide or Pyriproxyfen.

\section{A) Histopathology and ultrastucture of the integument.}

The integument of control last instar nymphs consists of the cuticle, hypodermis (or epidermis) and basement membrane. The cuticle is differentiated into an outer epicuticle and an inner endocuticle. The hypodermis consists of a single layer of cells, the boundaries between them are somewhat distinct and their function is to secrete the cuticle. The hypodermal cells stand upon a basement membrane (Fig. 1 a, b).

Fig. (2) demonstrates two electron micrographs for the Flufenoxuron-treated 1-day old last instar nymphs of $S$. gregaria. The treatment of 1-day old penultimate instar nymphs with $1000 \mathrm{ppm}$ resulted in some histopathological and ultrastructural effects because the production of endocuticle was blocked since its thickness remained unchanged while that of control congeners increased in thickness as the development proceeded to the last nymphal instar (see Fig. 1 for controls). 
As shown in Fig. (2), also, the newly formed cuticle in the treated last instar nymphs comprised only epicuticle and exocuticle which did not properly attached to the epidermis. Because of this detachment, the cuticle was very delicate and could not resist the muscular connection or the increasing turger during moulting process. In respect to the epidermis (or hypodermis), a single cellular epithelial layer was formed with cells irregularly distributed underneath the cuticle.

As seen in Fig. (3), some histopathological and ultrastuctural effects were recorded for Lufenuron on the last instar nymphs. The hypodermis was degenerated and detached from endocuticle. The latter could not distinguished from the exocuticle in the newly formed cuticle of these nymphs. Also, a distortion was quite visible in the endocuticle layers. The newly formed cuticle of treated nymphs was generally thinner than that of control congeners.

\section{B) Histopathology and ultrastructure of the thoracic muscles.}

The muscle fibrils consist of filaments distribution of which is related to the alternating light and dark bands. These bands give the muscle its striation pattern in which the $\mathrm{Z}$ line is commonly selected as marking the limits of the sarcomere. There are other bands in the sarcomere: isotropic band, I, which is bisected by the $Z$ line, and anisotropic band, A, which is bisected by a narrow light band, H. Also, a line M appears along the middle of the $\mathrm{H}$ band. At least, two kinds of filaments exist in the fibrils: prominent thicker filaments running along the A band and represent the protein, myosin; and less obvious filamentous thinner filaments extending from $\mathrm{Z}$ line to the edge of the $\mathrm{H}$ band which represents the actin (Fig. 4).

The treatment of 1-day old penultimate instar nymphs of S. gregaria with 1000 ppm Flufenoxuron resulted in some histopathological and ultrastuctural changes in the thoracic muscles of the 1-day old last instar nymphs. The electron micrograph (Fig. 5) shows degenerated muscles with disorganized components. The Z- disc appeared in an irregular and distorted shape. Also, the organization of A, I and $\mathrm{H}$ bands was disrupted. In addition, sarcomere had gaps and vacuoles.

In connection with the histopathological and ultrastuctural changes of the nymphal thoracic muscles by the action of Lufenuron, the electron micrograph in Fig. (6) reveals several symptoms of degenerated muscle fibers and complete distortion of Z-disc.

\section{B) Histopathology and ultrastructure of the mid-gut.}

The mid-gut of the control last instar nymphs of $S$. gregaria consists of an unicellular layer (epithelium) resting upon a basement membrane. This membrane is surrounded externally by circular and then by longitudinal muscle fibers. The epithelium consists of columner cells with clusters of small regenerative cells each of which contains a relatively large nucleus and strongly basophilic cytoplasm. The epithelium is, also, protected from the food particles by a detached sheath, peritrophic membrane, surrounding a lumen.

As seen in Fig. (7), the control (normal) mid-gut appears with luminal surface of the epithelium which is provided with a striated border constituting long microvilli. Such microvilli protect inwards into the lumen to increase the absorption surface of the cells, as well as, the spaces between them act as a kind of sieve.

The histopathological effects of Flufenoxuron on the mid-gut epithelium of 1-day old last instar nymphs of S. gregaria are demonstrated in Fig. (8). The electron micrographs show a destruction of the cell vacuolization and a rupture of the cell wall.

In respect to the histopathological effects of Lufenuron, the electron micrographs of Fig. (9) reveal some signs of morbidity in both nuclei and cytoplasm 
of the epithelial cells: microvilli of the columner cells were curled and ruptured, vacuolated cytoplasm with large area of necrosis.

C) Ultrastructure of the intracellular organelles.

The orientation of the mitochondria is said to depend on the nature of the cytoplasmic matrix, vacuolar system and the direction of the diffusion currents of the cell. The number of mitochondria in a cell depends on the type and functional state of the cell. It varies from cell to cell and from species to species. The mitochondria may be filamentous or granular in shape and may change from one form to another depending upon the physiological condition of the cells. Thus they may be of club, racket, vesicular, ring or round-shape. The size of the mitochondria ranges from 0.2 to $2.0 \mathrm{um}$ and the length may range from 0.3 to $40.0 \mathrm{um}$.

The mitochondria are bounded by a double membrane envelope which provides good tensile strength, stability and flexibility to them. The outer and inner mitochondrial membranes are 60-70 A thick. Each of them consists of outer and inner dense osmiophilic layers composed of protein molecules of 20 to $25 \mathrm{~A}$ thickness. Also, there is a middle (25 A thick) biomolecular layer composed of lipids (Fig. 10). Functionally, the mitochondria is described as a 'power house' in the cell.

Electron micrograph of the same figure shows the existence of rounded bodies taking the form of sac-like structures, each being surrounded by a single thin lipoprotein membrane. They breakdown cellular material such as protein, nucleic acid and polysaccharides. Such bodies are, therefore, known as lysosomes which can digest or lyse certain substances. The Golgi dictyosomes appear as flattened oval sac together with cluster of small vesicular bodies at their edges (for more details, see Fig. 7).

Electron micrographs of Fig. (8) reveal some ultrastructural changes by Flufenoxuron in the last instar nymphs of $S$. gregaria. The mitochondria appeared generally in an irregular shape. Their membranes were not demarkated with loss of cristae but increased granules (Fig. 11). Also, Flufenoxuron produced remarkably observed alterations in the morphology and topography of the Golgi bodies or dictysomes. In general, they were fragmented into small particles which were thinned out and gradually disappeared. The secretion granules associating the normal Golgi bodies, also, disappeared (Fig. 8).

The lysosomes considerably increased in number. Their limiting membranes were ruptured. The contained enzyme may be released causing destruction of the cellular constituents and complete dissolution of the cell. Hence, the lysosomes are also known as 'suicide bag' (Fig. 8). In addition, a great accumulation of secondary lysosomes in the nuclear region were caused by Flufenoxuron, some of which scattered in the cytoplasm (Fig. 8).

In connection with the nucleus, Flufenoxuron treatments resulted in a shrinkage and condensation of its coronation. The nuclear chromatin was released by the rupture of nuclear envelope while chromatin had disappeared from other parts of the nucleus. The margination of chromatin seemed to be a fairly early changed occurring in the nucleus after Flufenoxuron treatments leading to the cell death.

After the treatments of penultimate instar nymphs with Lufenuron, the ultrastructural examination of the last instar nymphs shows variable morphological pictures of mitochondria because cristae may be partially or even totally lost. Some mitochondria appeared swollen with irregular shape while other appeared greatly elongated with prominent cristae. The two mitochondria membranes were not demarkated and mitochondria had been filled with dark electron dense granules (Fig. 12). Some mitochondria had been seriously affected by Lufenuron and mitochondria 
were left. The cells had morbid and disintegrated nuclei which appeared in no definite shape. The nuclear membrane was disrupted (Fig. 9). Moreover, the lysosomes and Golgi bodies were hypertrophied and puffed with several deformations (see also Fig. 89).

\section{DISCUSSION}

\section{A) Histopathological Changes in the Body Tissues. \\ 1)The Integument.}

Various insect species belonging to several orders had been affected by chitin synthesis inhibitors (CSIs) as the histopathological changes of the integument revealed such effects (Ascher and Nemny, 1976; Metwally et al., 1978; Meola and Mayer, 1980; Mohsen et al., 1986; Bakr, 1986; Wang et al., 1987; Bakr et al., 1997; Yongdan and Liying, 2000; Sokolova et al., 2003; Xin et al., 2004). However, the literature contains several authorities for the histopathological effects of the pioneer CSI, diflubenzuron, on the integument of the Colorado potato beetle Leptinotarsa decemlineata (Grosscurt, 1978), the house fly Musca domestica (Bakr, 1986), the greenhouse whitefly Trialeurodes vaporaiorum (De Cock and Degheele, 1991, 1993), the mosquito Culex pipiens (Bakr et al., 1997), the lesser cotton leafworm Spodoptera exigua (Younes et al., 2000), etc...

In the present study, a concentration of $1000 \mathrm{ppm}$ of each of the CSIs Flufenoxuron or Lufenuron was given to 1-day old penultimate instar nymphs of $S$. gregaria and the electron micrographs show several histopathological changes in the integument of 1-day old last instar nymphs. Flufenoxuron caused a blockage of the production of cuticle since its thickness remained unchanged while that of control congeners increased in thickness as the development proceeded to the last nymphal instar. The formation of endocuticle was prohibited, so the epicuticle and exocuticle did not properly attached to the epidermis. The epidermis appeared with irregularly distributed cells underneath the cuticle.

On the other hand, Lufenuron exhibited more dangerous effects on the integument of 1- day old last instar nymphs. The epidermis was degenerated and detached from the endocuticle which could not be distinguished from the exocuticle. Also, the cuticle of treated nymphs was thinner than that of their control congeners.

These histopathological changes by Flufenoxuron and Lufenuron, to great extent, agree with those results recorded for some other CSIs on the same locust (Coppen, 1999; Tiwari, 2000; Kumari et al., 2001) and other insect species such as Lucilia cuprina (Binnington, 1985; Binnington et al., 1987), M. domestica (Awad and Mulla, 1984; El-Kordy, 1985), Agrotis ipsilon (Abdel-Al, 1996).

The present results, as shown in the available electron micrographs, may be substantiated by various findings of many works including some other CSIs for concluding that, the CSI affects the moulting process by prohibiting the epidermis function, distribution or blocking the production of certain cuticle layers. However, Meola and Mayer (1980) concluded that the cytostatic or antimitotic activity of CSIs on the cuticle formation is a direct or indirect.

\section{2) The Thoracic Muscles:}

All the insect muscles are built on a similar plan with elongate cells housing the contractile elements and, in many cases, inserted into the integument at either end. Each muscle is made up of a number of long fibers. Multinucleate cells usually run along the whole length of the muscle. The sarcolemma, myofibrils, sarcoplasm, 
molecular filaments, striation pattern (including discs and bands) and other structures are detailed in Elder (1975).

In hemimetabolous insects, such as the desert locust $S$. gregaria in the present study, a complete set of adult muscles is present in the nymphal form. Most muscles are in use during nymphal stage. Flight muscles, however, remain small and functionless until the last larval instar and develop rapidly just before and after the imaginal moult (Ready and Josephson, 1982; Novicki, 1989; Shiga et al., 2002).

Clearly, flight muscles belong to the best-studied insect muscles (Usherwoood, 1975), and one of the reasons for this might be that they are the most metabolically active tissue (Sacktor, 1970). All flight muscle fibers have short sarcomeres (2-4 um) and a rich supply of tracheae and numerous large mitochondria (Elder, 1975). Three principal types of flight muscle fibers were distinguished: a) tubular, b) close-packed, and c) fibrillar with the tubular and close-packed fibers belonging to the synchromous (or non-fibrillar) muscles (Biserova and Pfluger, 2004).

In the present study, the available electron micrographs reveal several dangerous effects of Flufenoxuron on the thoracic muscles of last instar nymphs of S. gregaria, such as distortion shape of the $\mathrm{Z}$ line and disorganization of $\mathrm{A}, \mathrm{I}$ and $\mathrm{H}$ bands, appearance of gaps and vacuoles in the sarcomere. More or less, similar effects were recorded for Lufenuron beside the complete distortion of the $\mathrm{Z}$ disc. However, similar or more serious histopathological changes by CSIs in the muscles of different insect species were recorded (Bakr, 1986; Pfluger et al., 1986; Wolf, 1990; Meuser and Pfluger, 1999; Biserova and Pfluger, 2004).

In the present study, the remarkably affected muscles by Flufenoxuron and Lufenuron, together with the lack of energy, may explain why the nymphs appeared in abnormal shape and failed to completely shed their exuvia or metamorphosed into adults with many morphogenic aberrations.

\section{3) The Mid Gut:}

The histopathology and ultrastructure of the alimentary canal, and the mid gut in particular, have revealed various effects of several insecticides and CSIs. Tappozada et al. (1968) investigated the histological and cytological changes in the mid gut of Spodoptera littoralis by some insecticides such as elongation of the epithelial cells, fading of cell boundaries and degeneration of some cells. Diflubenzuron blocked the production of peritrophic membrane in Locusta migratoria (Clarke et al., 1977). Decamethrin, diflubenzuron and methomyl caused vacuolation, elongation and breakdown of the epithelium, separation and detachment of peritrophic membrane of the pink bollworm Pectinophora gossypiella (Saad et al., 1985). Large vacuoles were observed in the epithelial layer of treated chironomid midges larvae ( Chironomous decorus Johansen and Tanypus gradhaus Sublette) fed on diflubenzuron and triflumuron (Pelsu, 1985). Similarly, in adult Tribolium castaneum fed on triflumuron, epithelium vacuoles were observed in the mid gut (Parween, 1997). The histopathological effects of some insecticides on the mid gut of Agrotis segetum were investigated by Ernic and Ayvali (1989). They recorded a destruction of epithelial and muscle cells at 6-10 h after treatment with trichorfan and disintegrated epithelial layer into the lumen after $18 \mathrm{~h}$ of treatment. The vacuolation, elongation and disintegration of the epithelial cells, as well as the disappearance of muscularis and regenerative cells, detachment of the basement membranes, ect ... had been observed in the mid gut of $S$. exigua by the action of diflubenzuron, malathion and cypermethrin (Younes et al., 2000). In addition, similar or other histopathological changes had been reported for some CSIs on different insects (Ker, 1977; Mitsui et al., 1980; Radwan et al., 1986). 
In the present histopathological study on the last instar nymphs of S. gregaria, the electron micrographs show several effects of Flufenoxuron such as the cell vacuolization and a rupture of the epithelial walls. In respect to Lufenuron, some signs of morbidity in both nuclei and cytoplasm of the epithelial cells were observed, such as curling and rupturing of the microvilli and the formation of large area of necrosis in a vacuolated cytoplasm. The vacuolization in the mid gut epithelium of treated nymphs was interpreted by Salkeld (1951) as a result of cell elongation, where the cytoplasm elasticity was lost.

The investigated effects in the present study may be informative to conclude that the CSIs Flufenoxuron and Lufenuron exhibited their dangerous histopathological effects on the mid gut of last instar nymphs of $S$. gregaria particularly after feeding on a food treated with a concentration of each. However, the mode of action needs to be investigated through further studies in future.

\section{B) Influenced Intracellular ultrastructure by Chitin Synthesis Inhibitors.}

Mitochondria are considered as the 'power house' of the living cell which supply energy for many chemical reactions and transport mechanisms in the cell. Orientation of mitochondria depends on the nature of the cytoplasmic matrix, vascular system and the direction of diffusion of currents in the cell. Their number and shape depend on the cell type and its physiological state varying from insect species to another. Each mitochondrium is bounded by a double membrane envelope which provides its tensile strength, stability and flexibility (Bakr, 1986 ).

After treatment of penultimate instar nymphs of $S$. gregaria with Flufenoxuron, in the present study, several ultrastructural changes were recorded. The mitochondria appeared generally in an irregular shape. Their two membranes were not demarcated with loss of cristae but increased granules. Morphology and topography of Golgi bodies was remarkably affected and some of them had been fragmented into small particles. The secretion granules associating the Golgi bodies disappeared. The limiting membranes of lysosomes were ruptured. The secondary lysosomes were accumulated in the nuclear region. The margination and nuclear chromatin seemed to be early changed leading to the cell death.

On the other hand, the present investigation revealed that Lufenuron caused many serious ultrastructural changes since the mitochondrial cristae were partially or totally lost. Some mitochondria appeared swollen with irregular shape while other appeared greatly elongated with prominent cristae. The mitochondrial membranes were not demarcated, and some mitochondria had been filled with dark electron dense granules. Also, the nuclear membrane was disrupted. As well as, the lysosomes and Golgi bodies were hypertrophied with different deformities. More or less, similar ultrastructural effects of different CSIs had been reported for various insect species (Meola and Mayer, 1980; Price and Stubbs, 1984; Wang et al., 1987; Bakr and Hussein, 1988; Khalaf, 1993; Bradly et al., 2001).

\section{REFERENCES}

Abdel-Al, A.E. (1996): Biological, histological and physiological effects of some insect growth regulators on the greasy cutworm, Agrotis ipsilon (Hufn) (Lepidoptera : Noctuidae). Unpublished M.Sc. Thesis, Cairo Univ., Egypt.

Ascher, K.R.S. and Nemny, N.E. (1976): Contact activity of diflubenzuron against Spodoptera littoralis larvae (Lepidoptera : Noctuidae). Pestic. Sci., 7(5) : 447-452 
Awad, T.I. and Mulla, M.S. (1984): Morphogenetic and histopathological effects induced by the insect growth regulator cyromazine in Musca domestica. J. Med. Entomol., 21(4) : 419-426.

Bakr, R.F.A. (1986): Morphogenic and physiological aberration induced by certain IGRs in the house fly Musca domestica. Unpublished Ph.D. Thesis, Ain Shams Univ. Cairo, Egypt.

Bakr, R.F.A. and Hussein, M.H. (1988): Morphogenic and histopathological studies on the effect of chitin synthesis inhibitor, chlorofluzuron against Musca domestica (L.) by using meethacrylate embedding technique. J.Egypt.Soc.Parasitol., 18(2): 635-646.

Bakr, R.F.A.; Isa, A.M.; Gabry, M.S. and Guneidy, A.M. (1997): Histopathological changes in Culex pipiens (Diptera: Culicidae) induced by juvenile hormone mimics. J.Egypt.Ger.Soc.Zool., 22(E): 27-45.

Binnington, K.C. (1985): Ultrastructural changes in the cuticle of the sheep blowfly, Lucilia cuprina induced by certain insecticides and biological inhibitors. Tissue and Cell, 17:131-140.

Binnington, K.C.; Retnakaran, A.; Stone, S. and Skelly, P. (1987): Studies on cyromazine and diflubenzuron in the sheep blowfly, Lucilia cuprina: inhibition of vertebrate and bacterial dihydrofolate reductase by cyromazine. Pestic.Biochem.Physiol., 27:201-210.

Biserova, N.M. and Pfluger, H.J. (2004): The ultrastructure of locust pleuroaxillary "steering" muscles in comparison to other skeletal muscles. Zoology, 107(3):229-242.

Bradley, J.T.; Kloc, M.; Wolfe, K.G.; Estridge, B.H. and Bilinski, S.M. (2001): Balbiani bodies in cricket oocytes: development, ultrastructure and presence of localized RNAs. Differentiation, 67(4/5):117-127.

Brissan, A.; Gharibian, S.; Agen, R.; Leclerc, D.F. and Breuil, C. (1996): Localization and characterization of the melanin granules produced by the sap-staining fungus Ophiostoma piceae. Material and Organismen, 30:2332.

Casida, J.P. and Quistad, G.B. (1998): Golden age of insecticide research: past, present and future. Annu.Rev.Entomol., 43:1-16.

Clark, L.; Tempale, G.H.R. and Vincent, J.F.V. (1977): The effects of chitin inhibitor - Dimilin on the production of peritrophic membrane in locust, Locusta migratoria. J. Insect Physiol., 23 : 241-246.

Coppen, G.D.A. (1999): A simple model to estimate the optimal separation and swath width of Ulv-sprayed barriers of chitin synthesis inhibitors (CSI) to control locust hopper bands. Crop Protec., 18:151-158.

De Cock, A. and Degheele, D. (1991): Cytochemical demonstration of chitin incorporation in the cuticle of Trialeurodes vaporariorum (West Wood) (Homoptera : Aleyrodidae) buprofezin treatment. Int. J. Insect Morphol. Embryol., 22(2-4): 119-125.

De Cock, A. and Degheele, D. (1993): Effects of buprofezin on the ultrastructure of the third instar cuticle of the insect Trialeurodes vaporariorum. Tissue and Cell, 23(5):755-762.

DeLoach, J.R.; Meola, S.M.; Mayer, R.T. and Thompson, J.M. (1981): Inhibition of DNA synthesis by diflubenzuron in pupae of the stable fly Stomoxys calcitrans (L.) Pest. Biochem. Physiol., 15:172. 
Deul, D.J.; de Jong, B.J. and Kortenback, J.A.M. (1978): Inhibition of chitin synthesis by two 1-(2,6-disubstituted benzoyl)-3-phenylurea insecticides. Pest. Biochem. Physiol., 8 : 98-105.

Elder, H.Y. (1975): Muscle structure. In "Insect Muscles (Usherwood, P.N.R., ed). Academic Press, London, pp: 1-74.

El-Kordy, M.W.A. (1985): The effect of some growth regulators on Musca domestica (L.). Unpublished Ph.D. Thesis, Fac.Agric., Al-Azhar Univ., Cairo, Egypt.

Ernic, M. and Ayvali, C. (1989): Histopathological effects of some insecticides on the midgut of Agrotis segetum (Denis et Schiff.) (Lepidoptera: Noctuidae). Seker,35(124):22.

Gijswijt, M.J.; Deul, D.H. and DeJong, B.J. (1979): Inhibition of chitin synthesis by benzoylphenylurea insecticides, III. Similarity in action in Pieres brassicae (L.) with polyxin D. Pestic. Biochem. Physiol., 12:84-94.

Grosscurt, A.C. (1978): Diflubenzuron : some aspects of its ovicidal and larvicidal mode of action and an evaluation of its practical possibilities. Pestic. Sci., 9:373-386.

Hammock, C.D. and Quisted, G.B. (1981): Meabolism and mode of action of juvenile hormone, juvenoids and other insect growth regulators. In "Progress in pesticide Biochemistry" (Hutson, D.H. and Roberts, T.R. eds.), Vol. 1, pp. 1-85, John Wiley \& Sons Ltd.

Hassanein, M.S. (1965): Laboratory and outdoor cultures and breeding of locusts and grasshoppers. FAO Publ., 5/31901, 10 pp.

Hunter-Jones, P. (1961): Rearing and breeding locusts in laboratory. Bull. Anti-locust Res. Cent. Lond., 12 pp.

Ishaaya, I. (1990): Benzoylphenyl ureas and other selective insect control agentsmechanism and application. In "Pesticides and Alternatives" (Casida, J., ed)., pp. 365-376, Elsesvier Sci. Publ. Biomid. Divi., Amesterdam.

Ishaaya, I. and Ascher, K.R.S. (1977): Effects of Diflubenzuron on growth and carbohydrate hydrolases of Tribolium castaneum. Phytoparasitica, 5:149158.

Ker, R.F. (1977): Investigation of locust cuticle using the insecticide Diflubenzuron. J. Insect Physiol., 73:556-560.

Khalaf, A.A.A. (1993): Effect of some insect growth regulators on certain biological, histological and physiological aspects of the fly Synthesiomyia nudiseta Wulp (Diptera : Muscidae). Unpublished Ph.D. Thesis, Fac. Sci., Zagazig Univ. Egypt.

Kumari, A.; Kumar, U. and Agawal, H.C. (2001): Inhibitory effects of 1-benzyl5[(c)-2,6-dimethyl-1,5-heptadienyl] imidazale (KK-42) on desert locust Schistocerca gregaria (Forsk.). Indian J. Exp. Biol., 39:811-813.

Meola, S.M. and Mayer, R.T. (1980): Inhibition of cellular proliferation of epidermal cells by diflubenzuron in pupae of the stable fly. Science (Wash.), 207 (4434) : 985-987.

Metwally, E.S.M.; Sallam, S. and Gohar, K. (1978): Histological changes in the larvae of the cotton leafworm by sublethal doses of three insecticides. Proc. 4th Conf.Pest Control, N.R.C., 1: 401-405.

Meuser, S. and Pfluger, H.J. (1999): Programmed cell death specifically eliminates one part of a locust pleuroaxillary muscle after imaginal moult. J. Exp.Biol., 201: 2367-2382. 
Mitsui, T.; Nobusawa, C.; Fokami, T.I.; Collins, I. and Riddiford, L.M. (1980): Inhibition of chitin synthesis by diflubenzuron in Manduca larvae. J. Pest. Sci., 5:335-341.

Mohsen, Z.H.; Zahid, Z.R.; Al-Chalabt, B.; Mehdi, N.S. (1986): Biological activity of the IGR, diflubenzuron on the larvae of Culex quinquefaciatus (Say.). J. Biol.Sci.Res., 17(1): 279-288.

Novicki, A. (1989): Control of growth and ultrastructural maturation of a cricket flight muscle. J. Exp.Zool., 250: 263-272.

Parween, S. (1997): Effect of triflumuron on the adult mid gut of Tribolium castaneum (Herbst.) (Coleoptera : Tenebrioidae). Univ. J. Zool. Rajshahi Univ., 16:11-18.

Pelsu, F.W. (1985): Histopathological effects of two insect chitin inhibitors in the alimentary canal of chironomid midges (Diptera: Chironomidae). Bull.Soc.Vector Ecol., 10(2): 72-89.

Pfluger, H.J.; Elson, R.; Binkle, U.; Schneider, H. (1986): The central nervous organization of the motor neurons to a steering muscle in locusts. J.Exp.Biol., 120: 403-420.

Price, N.R. and Stubbs, H.R. (1984): Some effects of CGA-72662 on larval development in the house fly Musca domestica. Integument.J. Invert.Repr.Develop., 7:119- 126.

Radwan, H.S.A.; Assal, O.M.; Abo El-Ghar, G.E.; Riskallah, M.R.; Ahmed, M.T. (1986): Some aspects of the action of diflubenzuron and trifluron on food consumption, growth rate and food utilization by Spodoptera littoralis larvae. J. Insect Physiol., 32(2): 103-107.

Ready, N.E.; Josephson, R.K. (1982): Flight muscle development in a hemimetabolous insect. J.Exp.Zool., 220:49-56.

Reynolds, S.E. (1963): The use of lead citrate at high $\mathrm{pH}$ as an electron opaque stain in electron microscopy. J. Cell Biology, 1:208.

Saad, A.S.A.; Lahny, M.H.E.; Awad, H.A.; Radwan, H.A. (1985): Histopathological studies of certain pesticides on pink bollworm Pectinophora gossypiella. Proc0 $6^{\text {th }}$ Arab Pest. Conf., Tanta Univ., Egypt, 1:77-91.

Sacktor, B. (1970): Regulation of intermediary metabolism with special reference to the control mechanisms in insect flight muscle. Ad. Insect Physiol.,7:267347.

Salama, H.S.; Motagally, Z.A. and Skatulla, U. (1976): On the mode of action of Dimilin as a moulting inhibitor in some lepidoptrous insects. J. Appl. Entomol., 80:396-407.

Salkeld, E.H. (1951): A toxicological and histophysiological study of certain new insecticides as "stomach poisons" to the honey bee Apis mellifera L. Canad.Ent., 83:39-61.

Shiga, S.; Yauyama, K.; Okamura, N. and Yamaguchi, T. (2002): Natural and endocrine control of flight muscle degeneration in the adult cricket, Gryllus bimaculatus J. Insect Physiol., 48(1):15-24.

Sokolova, Y.Y.; Dolgikh, V.V.; Morzhina, E.V.; Nassonova, E.S.; Issi, I.V.; Terry, R.S.; Ironside, J.E.; Smith, J.E.; Vossbrinck, C.R. (2003): Establishment of the new genus Paranosema based on the ultrastructure and molecular phylogeny of the type species Paranosema grylli Gen.Nov., Comb.Nov. (Sokolova, Selezniov, Dolgikh, Issi, 1994). J. Invert. Pathology, 84(3): 159172. 
Soltani N.; Besson, M.T. and Delachambre, J. (1993): Penetration and insecticidal activity of diflubenzuron in Tenebrio molitor pupae. Pestic. Sci., 14:625632.

Spnrr, A.R. (1969): A low viscosity epoxy resin embdding medium for electron microscopy. J. Ultrastruc. Res., 26:31-43.

Tappozada, A.; Salama, A.E.; El-Defrawi, M.E.; Zeid, M. (1968): Histopathological effects of insecticides on the midgut of Egyptian cotton leafworm Spodoptera littoralis. Ann.Ent.Soc.Amer., 61(5): 1326-1333.

Tiwari, L.D. (2000): Toxicity of chlorfluzuron to fifth instar hoppers of Schistocerca gregaria. Indian J. Ent., 62(2): 211-213.

Usherwood, P.N. (1975): Insect Muscle. Academic Press, London.

Verloop, A. and Ferrel, C.D. (1977): Benzoylureas - a new group of larvicides interferring with chitin deposition. In "Pesticide chemistry in the $20^{\text {th }}$ Century" (Plummer, J.R., ed.). Acs symposium series 37, pp: 237-270, Whashington, D.C., Amer. Chem.Soc.

Wang, C.H.; Ho, C.M.; Hsu, T.R.; Wu, J.Y. (1987): Effect of Dimilin, a chitin synthesis inhibitor on the growth and development of Aedes albopictus Skuse. J. Entomol. Honghua Kunchong, 7(2): 131-141.

Wolf, H. (1990): On the function of a locust flight steering muscle and its inhibitory innervations. J.Exp.Biol.,150:55-80.

Xin, J.; Shangan, Z.; Long, Z. (2004): Ultrastructure of four types of antennal sensilla in Locusta migratoria manilensis (Orthoptera: Acrididae). J.Agric.Biotech., 12(3): 300-305.

Yongdan, L. and Liying, W. (2000): Ultrastructure and DNA restriction endonuclease analysis of Calliptomus italicus entomopoxvirus. Entomologia Sinica, 7(4): 329-336.

Younes, M.W.F.; Abou El-Ela; R.G. and El-Mhasen, M.A. (2000): Histopathological effects of some insecticides on the larval midgut and integument of the lesser cotton leafworm Spodoptera exigua (HB) (Lepidoptera : Noctuidae). J. Egypt Ger. Soc. Zool., 32:19-31.

$\mathrm{Yu}$, S.J. and Terriere, L.G. (1975): Activities of hormone metabolizing enzymes in house flies treated with some substituted urea growth regulators. Life Sci., 17:619-628. 

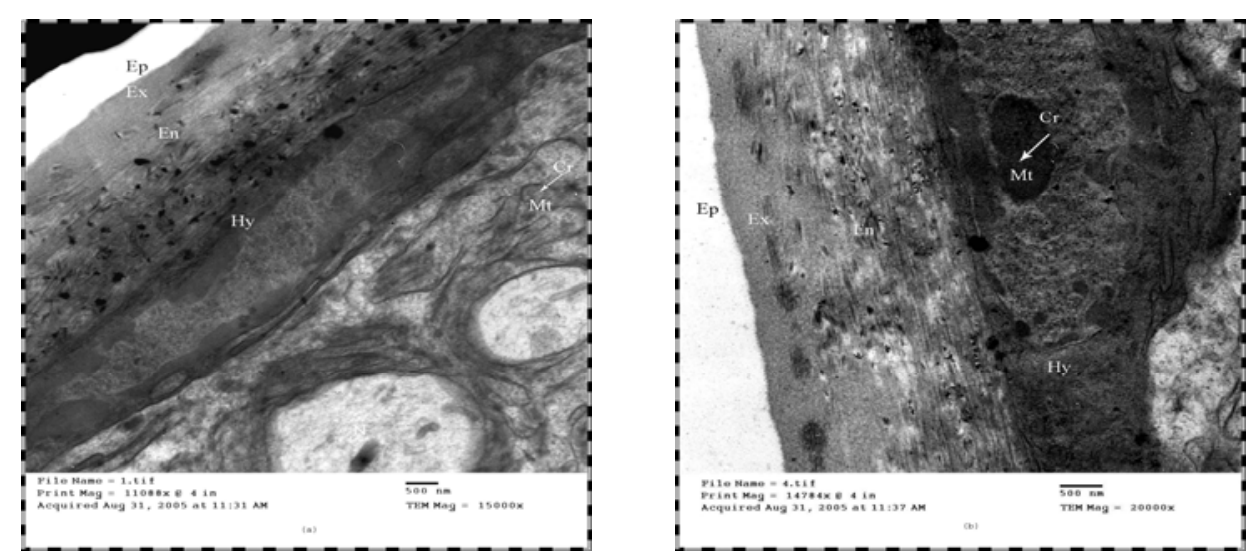

Fig. (1): Electron micrographs of transverse sections through two sites ( $a \& b$ ) of the integument of control 1- day old last instant nymphs of Schistocerca gregaria. Abreviations: Ep: epicuticle, Ex: exocuticle, En: endocuticle, Mt: mitochondria, Cr: mitochondrial cristae
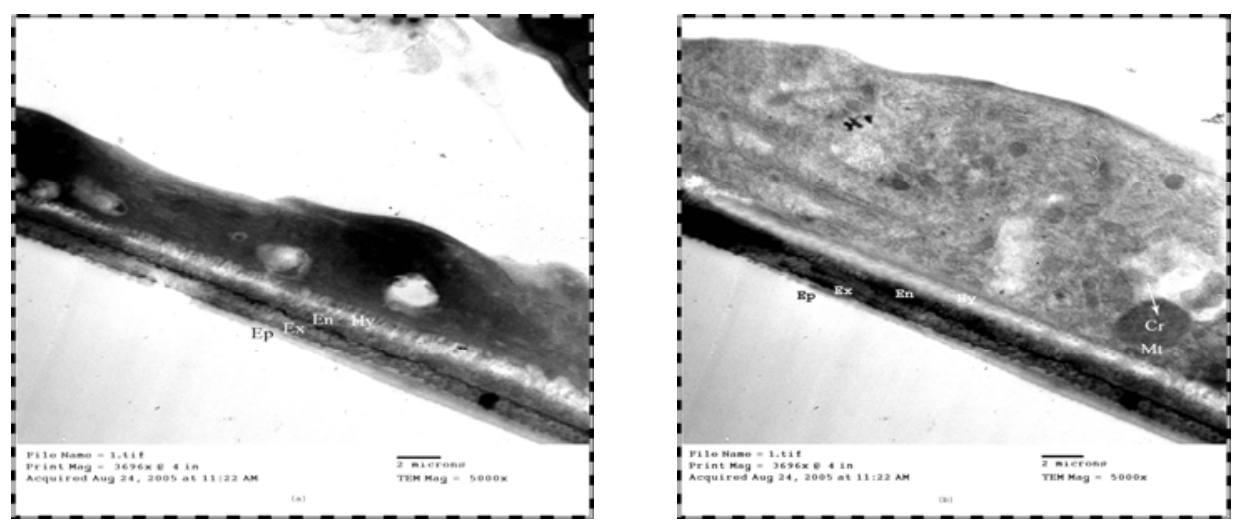

Fig. (2): Electron micrographs of transverse sections through two sites $(a, b)$ of the integument of Flufenoxuron - treated last instar nymphs of Schistocerca gregaria. The production of endocuticle was blocked since its thickness remained unchanged through the development. Epicuticle and exocuticle did not properly attached to the epidermis. Epidermal cells were irregularly distributed underneath the cuticle. Abbreviations: Ep: epicuticle, Ex: exocuticle, En: endocuticle, Hy: epidermis (or hypodermis).
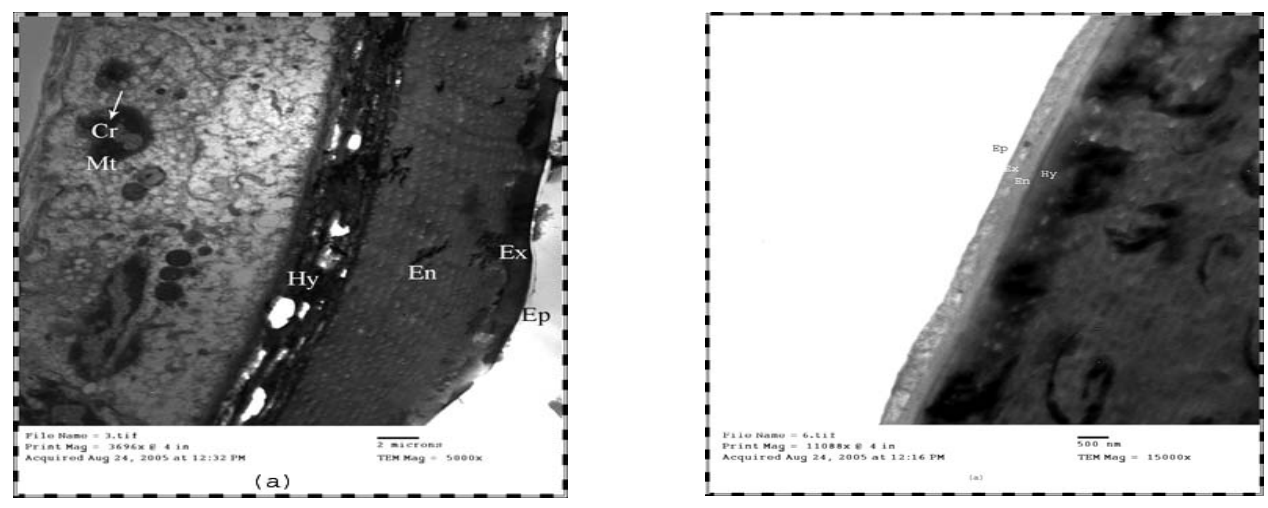

Fig. (3): Electron micrographs of transverse sections through two sites $(a, b)$ of the integument of Lufenuron - treated last instar nymphs of Schistocerca gregaria. Hypodermis was degenerated and detached from the endocuticle. Exocuticle can not be distinguished in the newly formed cuticle. Also, a distortion is quite visible in the endocuticle layers. Abbreviations: Ep: epicuticle, Ex: exocuticle, En: endocuticle, Hy: epidermis (or hypodermis). 


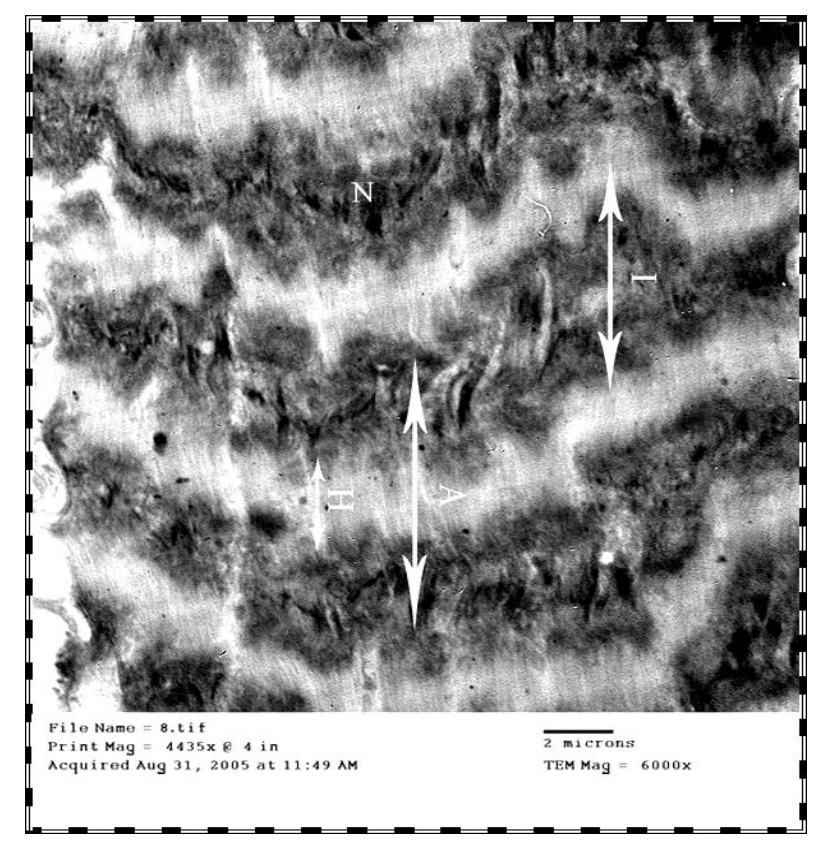

Fig. (4): Electron micrograph of a longitudinal section of the thoracic muscles of control 1- day old last instar nymphs of Schistocerca gregaria Abbreviation: I: isotropic band, A: anisotropic band, M: middle band, H: narrow light band, Z: marked limits of sarcomere.

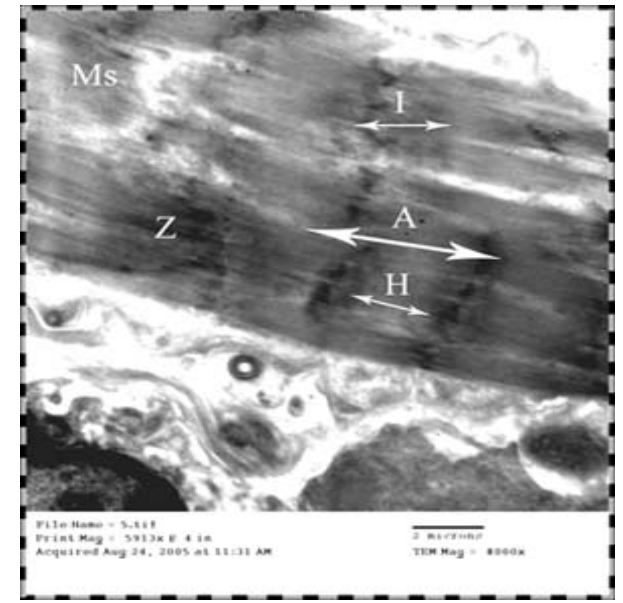

Fig. (5): Electron micrograph of a longitudinal section of the thoracic muscles of Flufenoxuron - treated last instar nymphs of Schistocerca gregaria. The Z- disc appeared in an irregular and distorted shape. Also, the organization of $A, I$ and $H$ bands was disrupted. Abbreviations: I: isotropic band, A: anisotropic band, $M$ : middle band, $H$ : narrow light band, Z: marked limits of sarcomere.

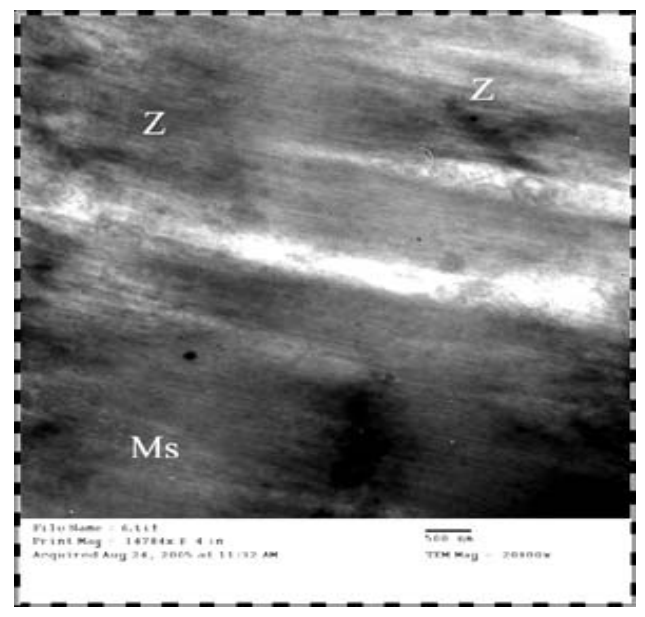

Fig. (6): Electron micrograph of a longitudinal section of the thoracic muscles of Lufenuron - treated last instar nymphs of Schistocerca gregaria. Degenerated muscle fibers and complete distortion of Z- disc can be observed. Abbreviations: Z: marked limits of sarcomere, Ms: muscles. 

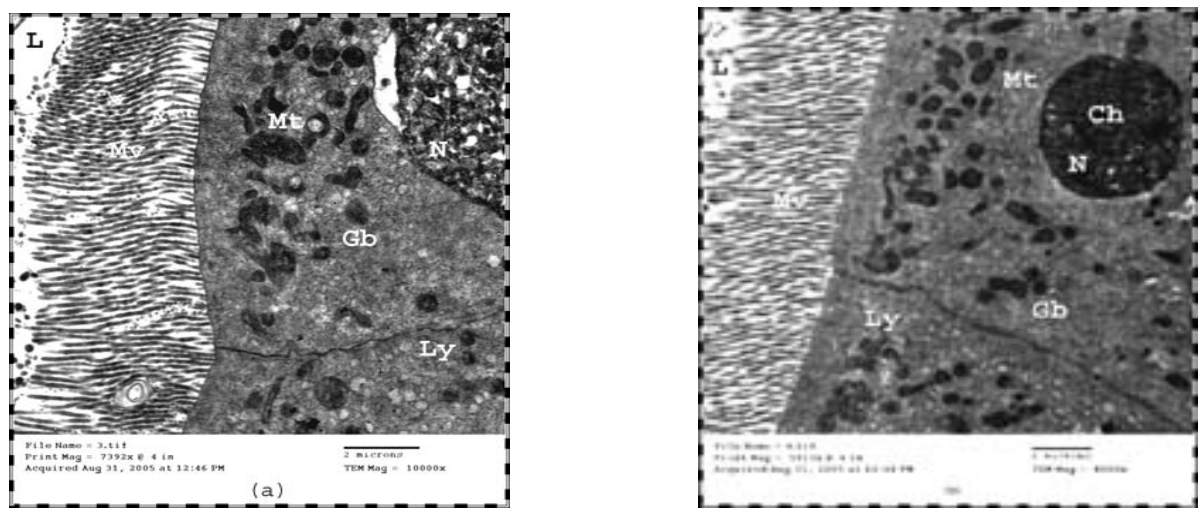

Fig. (7): Electron micrographs of transverse sections through two sites ( $a$ \& $b$ ) of the mid gut of control 1- day old last instant nymphs of Schistocerca gregaria. Abbreviations: L: Lumen cavity, Gb: Golgi bodies, N: nucleus, Ly: Lysosome, Mv: microvilli.
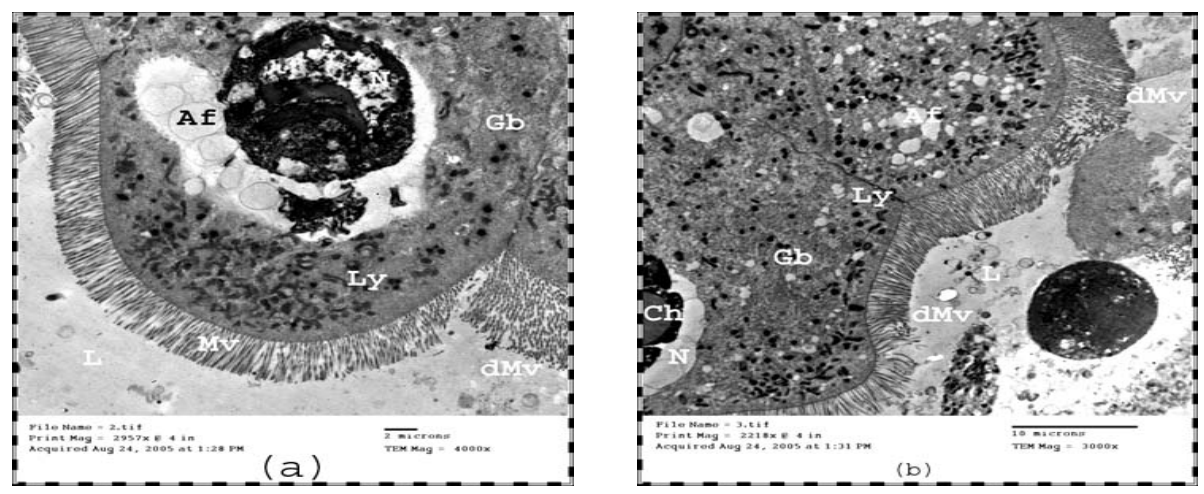

Fig. (8): Electron micrographs of transverse sections through two sites ( $a$ \& $b$ ) of the mid gut of Flufenoxuron - treated last instar nymphs of Schistocerca gregaria. A destruction of the cell vacuolization and a rupture of the cell wall can be easily observed. Also, alterations in the morphology and topography of the Golgi bodies can be seen. The lysosomes considerably increased in number, nucleus can be seen as shrinked with condensed coronation. Abbreviations: dMv: destruction of microvilli, Ly: lysosome, Gb: Golgi bodies, $N$ : nucleus, L: lumen cavity, AF: autophagic vacuoles.
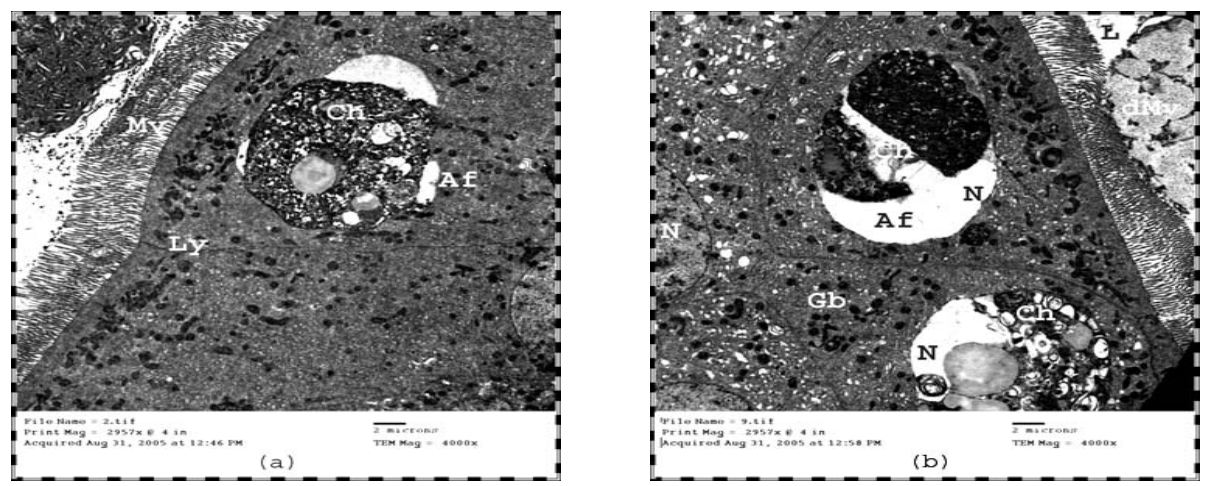

Fig. (9): Electron micrographs of transverse sections through two sites ( $a$ \& $b$ ) of the mid gut of Lufenuron - treated last instar nymphs of Schistocerca gregaria. Morbidity in both nuclei and cytoplasm of the epithelial cells can be observed. Also, the microvilli of columnar cells were ruptured and appeared in a curled shape. A vacuolated cytoplasm can be seen with a large area of necrosis. The nuclear membrane was disrupted . Lysosomes and Golgi bodies were hypertrophied and puffed with several deformations. Abbreviations: Ly: lysosome, Mr: microvilli, Ch: chromatin, N: nucleus. 


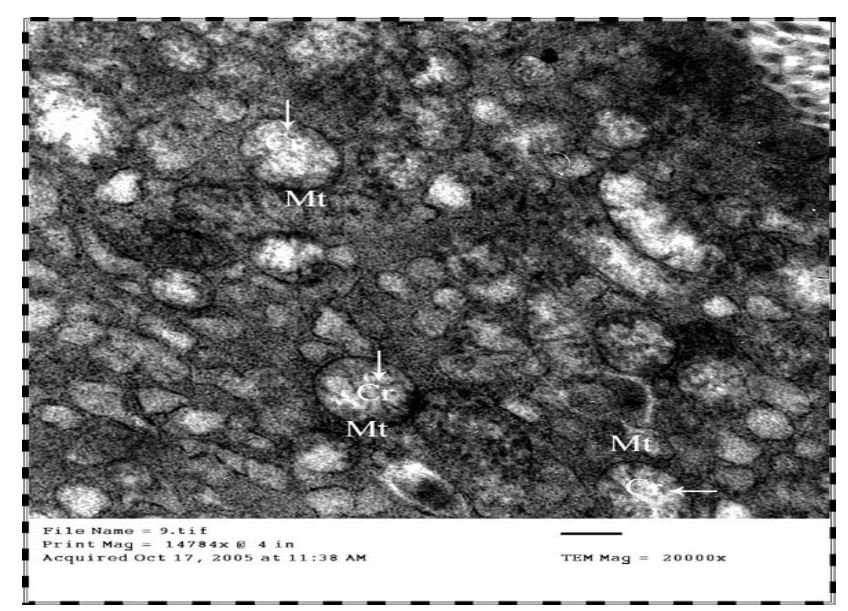

Fig. (10): Electron micrograph of mitochondria in control $\overline{1}-\bar{d}$ day old last instar nymphs of Schistocerca gregaria. Abbreviations: Mt: mitochondria, Cr: cristae.

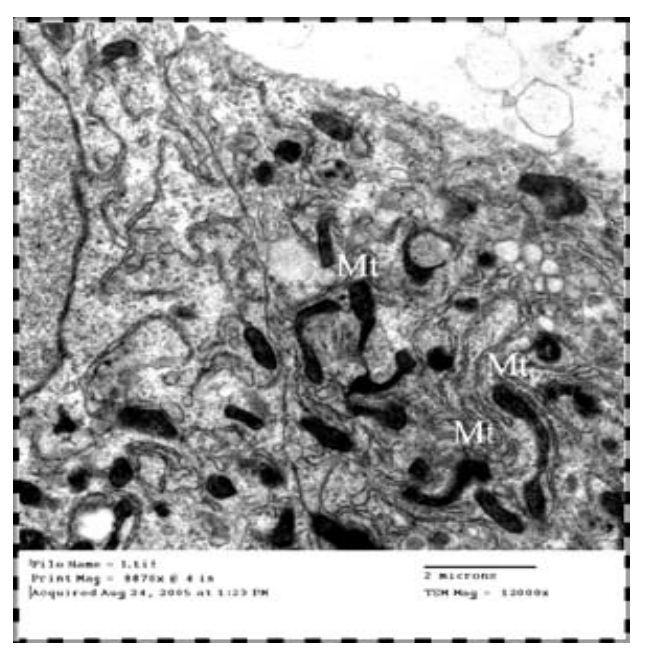

Fig. (11): Electron micrograph of mitochondria in Flufenoxuron - treated last instar nymphs of Schistocerca gregaria. The mitochondria generally appeared in an irregular shape. Their membranes were not demarcated with loss of cristae. Abbreviations: Mt: mitochondria, Cr: cristae.

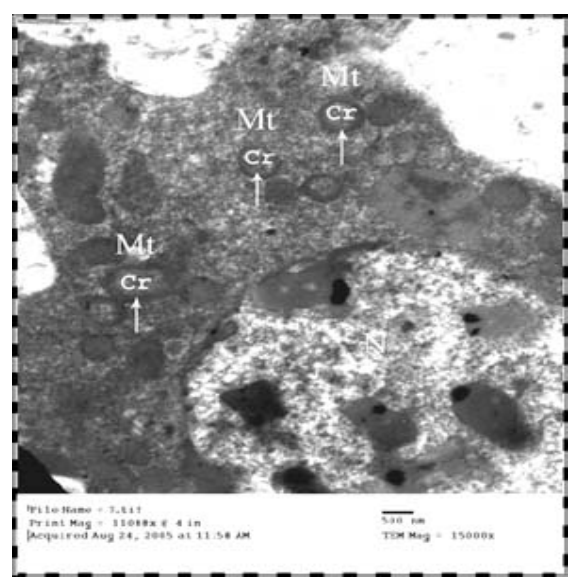

Fig. (12): Electron micrograph of mitochondria in Lufenuron - treated last instar nymphs of Schistocerca gregaria. Variable morphological pictures of mitochondria can be shown. Cristae may be partially or even totally lost. Some mitochondria appeared swollen with irregular shape and other appeared greatly elongated with prominent cristae. Abbreviations: Mt: mitochondria, Cr: cristae. 


\title{
ARABIC SUMMERY
}

التغيرات التركيبية الدقيقة في أنسجة معينة لحوريات الجراد الصحراوي شيستوسركا جريجاريا (مستقيمات الأجنحة: الجراديات) بفعل بعض مثبط أنجات تخليق الكيتين

رضا فضيل بكر 1، كارم السيد غنيم²، أحمد صابر بريم²، علاء جودة الدالي، محمد علي طناني2

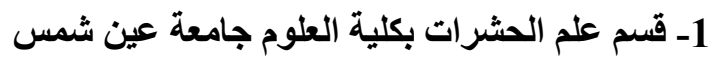 \\ 2- قسم علم الحيوان بكلية العلوم جامعة الأزهر، القاهرة
}

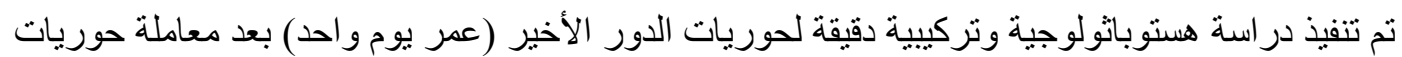
الدور قبل الأخير( عمر يوم واحد) بتركيز 1000 ج.ف.

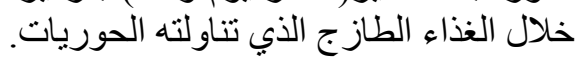

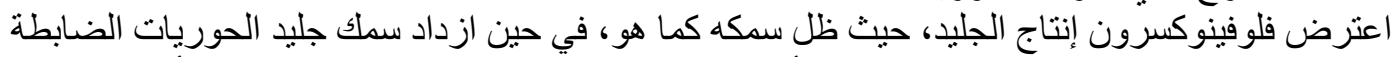

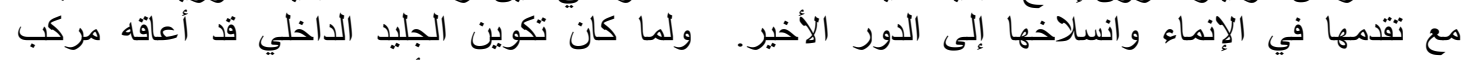

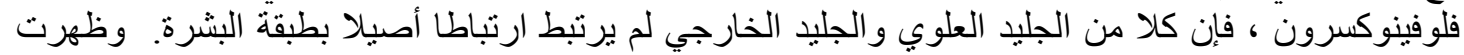

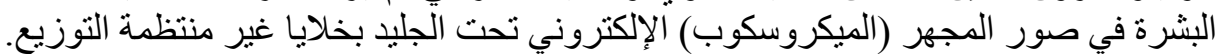

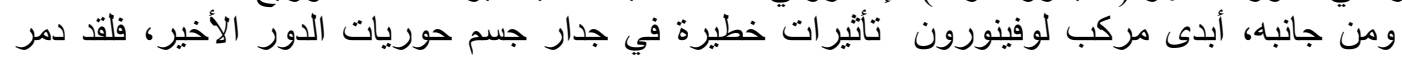

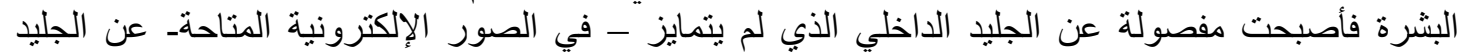

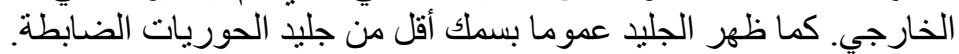

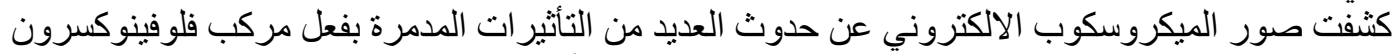

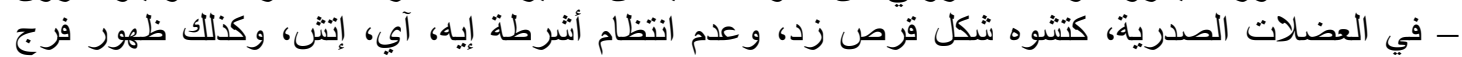

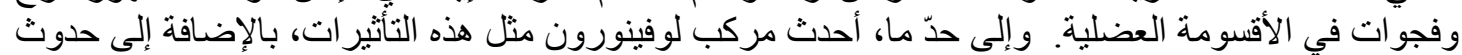

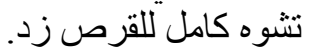

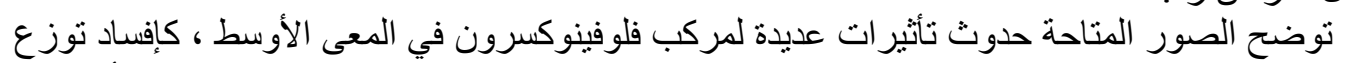

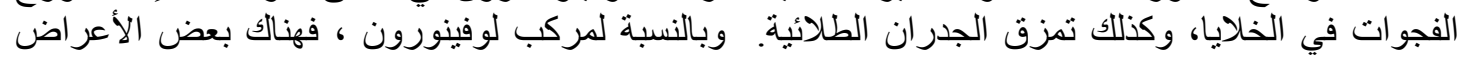

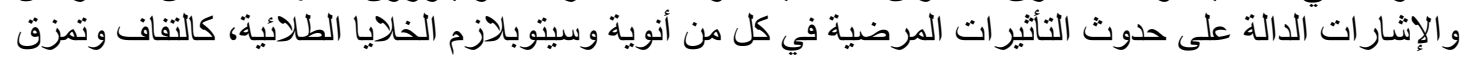

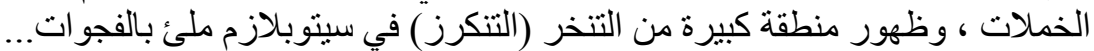

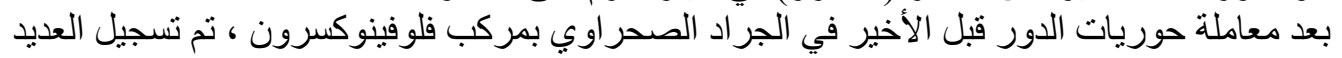

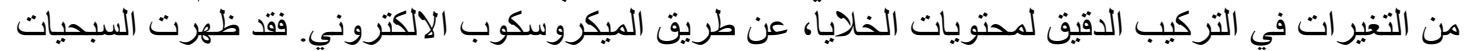

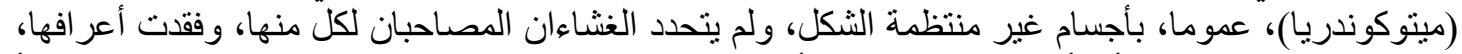

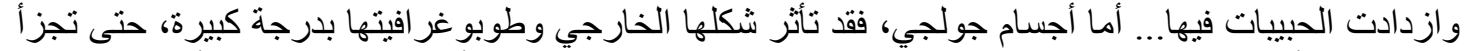

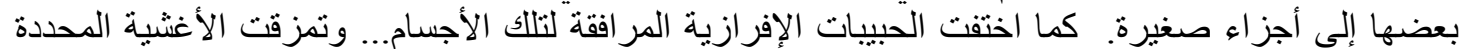

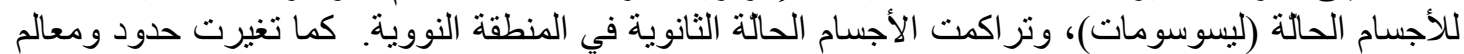

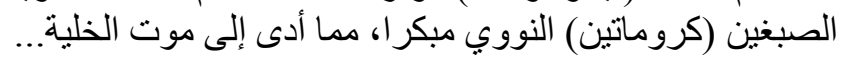

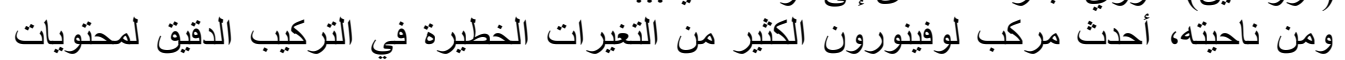

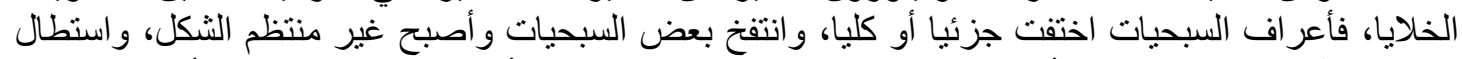

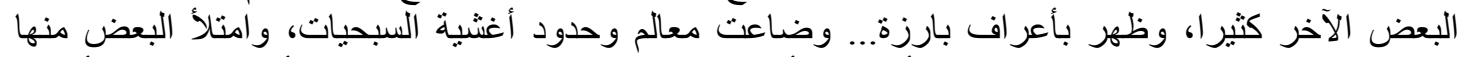

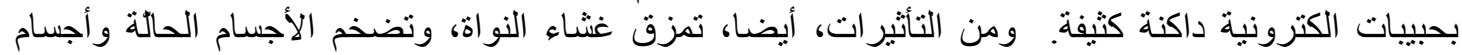
جولجي، التي ظهرت بها تشو هات مختلفة. 